\title{
MESOSSISTEMA ESCOLA-FAMÍLIA: IMPACTO NO DESENVOLVIMENTO INTEGRAL DA CRIANÇA
}

\section{ARTIGO ORIGINAL}

ROOS, Marcia Sabrina Roos de ${ }^{1}$, TRUCCOLO, Adriana Barni²

ROOS, Marcia Sabrina Roos de. TRUCCOLO, Adriana Barni. Mesossistema escola-família: impacto no desenvolvimento integral da criança. Revista Científica Multidisciplinar Núcleo do Conhecimento. Ano: 06, Ed. 08, Vol. 02, pp. 97118. Agosto 2021. ISSN: 2448-0959, Link de acesso: https://www.nucleodoconhecimento.com.br/educacao/integral-da-crianca, $\quad$ DOI: 10.32749/nucleodoconhecimento.com.br/educacao/integral-da-crianca

\section{RESUMO}

A família e a escola são microssistemas por onde a criança transita levando consigo as experiências ora vivenciadas no ambiente familiar, ora vivenciadas nas interações construídas no ambiente escolar. Vínculos afetivos são criados nesses dois potentes e potenciais espaços de desenvolvimento da criança. $\mathrm{Na}$ família irão ocorrer as primeiras e principais interações sociais da criança, sendo considerada sua primeira fonte de informação. A Escola é o segundo espaço de convívio social das crianças e onde serão estabelecidas as interações com os pares e os professores. Tanto a família quanto a escola são as referências da criança e será o grau de afinidade entre ambas, que impactará positivamente no seu desenvolvimento e formação. Assim, surgiu a seguinte questão de pesquisa: Existe interação entre as famílias de escolares do terceiro ano do ensino fundamental e a escola estadual a que pertencem? O objetivo geral deste estudo foi identificar em que situações ocorre a participação das famílias de escolares do terceiro ano do ensino fundamental junto à

\footnotetext{
${ }^{1}$ Licenciatura em Pedagogia.

${ }^{2}$ Orientadora. Mestre em Health Education (USA); Mestre em Ciências da Saúde - Cardiologia (Fundação Universitária de Cardiologia do RS).
}

RC: 93528

Disponível em: https://www.nucleodoconhecimento.com.br/educacao/integral-dacrianca 
escola. Pesquisa com abordagem qualitativa, descritiva com relação aos objetivos, de campo com relação aos procedimentos técnicos, tendo como instrumento de coleta dos dados a observação não participante e entrevistas semiestruturadas. A amostra foi composta por 17 crianças, uma professora e nove pais ou responsáveis. Os dados foram coletados em uma escola pública estadual e foram analisados a partir da construção de eixos de análise: eixo criança, eixo professora e eixo família. Constatou-se que a participação ativa da família no ambiente escolar promove conforto e segurança para as crianças, e os procedimentos pedagógicos adotados pela equipe diretiva levam em conta sugestões de algumas famílias, no sentido de promover às crianças um ambiente favorável ao desenvolvimento de suas capacidades. As famílias comparecem à escola principalmente para saber acerca do grau de aproveitamento da criança nas aulas, sendo importante o aprendizado de conteúdo. Conclui-se que o mesossistema escola-famílias impacta diretamente no desenvolvimento integral da criança, sendo o ambiente familiar um potente influenciador do aprendizado da criança e a escola o local de acolhimento dessa criança que é única em experiências vividas.

Palavras-chave: Criança, Famílias, Escola, Vínculo.

\section{INTRODUÇÃO}

Segundo a Pesquisa Nacional por Amostra de Domicílios Contínua Anual, no $2^{\circ}$ semestre de 2019, o percentual de crianças e adolescentes entre seis e 14 anos frequentando o ensino fundamental era de $97,3 \%$ no Brasil e $97,4 \%$ na região Sul do país (IBGE, 2020). Entretanto, 1,5 milhão de crianças e adolescentes permaneciam fora da escola (UNICEF, 2021).

Com a pandemia do Covid-19 em 2020 as escolas fecharam, pelo menos, presencialmente; e em novembro de 2020, mais de cinco milhões de crianças estavam sem acesso à educação no Brasil - "número semelhante ao que o País tinha no início dos anos 2000." Acrescenta-se que mais de $40 \%$ desses cinco 
milhões são de crianças entre 6 e 10 anos de idade, etapa em que a escolarização estava praticamente universalizada antes da Covid-19 (UNICEF, 2021).

Com as escolas fechadas, a desigualdade social do país, oriunda de contextos socioeconômicos e sociais, mostrou a sua face de forma mais ostensiva revelando em números absolutos que $71,3 \%$ das crianças e adolescentes de 4 a 17 anos que não frequentavam a escola antes da pandemia são autodeclaradas(os) pretas(os), pardas(os) e indígenas. Esses, ficaram ainda mais distantes de seu direito de aprender, e aqueles que estavam matriculados, contudo, sem acesso à internet, ou tendo agravada a situação de pobreza acabaram sendo distanciados de seu direito à educação (UNICEF, 2021; FUNDAÇÃO ABRINQ, 2021).

Após um ano de pandemia do coronavírus as escolas reabrem timidamente, recebendo nem todos os alunos ao mesmo tempo. Nada é igual a antes. As crianças não se abraçam e nem à professora, estão distantes uma das outras, usam máscaras, passam álcool gel na entrada, na saída. Tudo está diferente. Os pais, as mães, os responsáveis precisam trabalhar e lidar, ao mesmo tempo, com os afazeres da casa, as compras e saídas restritas, as preocupações financeiras, com a criança que ficou em casa, com a criança que foi para a escola. Todos acabaram trabalhando mais, pais, mães, responsáveis e professoras (res). Algumas escolas continuam com ensino remoto, e a família tem tido uma participação ativa nos estudos, ou pelo menos, algumas famílias. Claro que, isso é o que se espera que esteja acontecendo, pois mais do que nunca esse apoio familiar é importante para que a criança tenha condições de estudar virtualmente. São novas experiências e aprendizagens em todos os espaços, tanto escolar, quanto familiar. Período esse, de estreitar os laços para que possa superar tudo isso. Assim como a escola e professores precisaram se reinventar, as famílias precisaram de uma maior aproximação com as escolas, indo buscar material impresso nas mesmas quando sem acesso à internet, auxiliando as crianças nos temas, convivendo mais com o universo escolar. Mais do que nunca possibilitar que a criança não perca o vínculo com a escola se tornou objetivo de todos. A pandemia do coronavírus trouxe muitas 
incertezas e uma forte percepção de ter aproximado as famílias das escolas, sendo primordial que se comuniquem e mantenham um diálogo aberto e sincero a fim de evitar a exclusão escolar e manter o bem-estar da criança.

Importante salientar que cada criança que chega à escola vem de uma família diferente, com experiências distintas, com cores distintas, algumas delas de um padrão tradicional de organização família nuclear - um casal heterossexual, unido pelo casamento e criando todos seus filhos biológicos. Outras, vêm de modelos de família reconfiguradas, que coexistem com uma gama de outros arranjos familiares ricos em complexidade, tais como as famílias homo parentais ou homoafetivas, famílias monoparentais, famílias recompostas ou reconstituídas (FREITAS; ANJOS, 2020). Há mãe e pais solteiros, adoções, produção independente, fertilização in vitro (FELIPPI; ITAQUI, 2015). Assim, não tem sentido de se falar em família, mas sim em famílias. E são crianças advindas dessas distintas configurações familiares que chegam à escola e convivem com outras crianças de outras famílias, construindo laços afetivos, misturando-se a outros mundos, tão necessários para o seu crescimento interpessoal.

Dentro desse contexto, da possibilidade de diferentes configurações de família, o termo parentalidade se destaca, uma vez que se distingue por um conjunto de ações realizadas pelas figuras parentais, com a intenção de promover o desenvolvimento integral da criança e do 16 adolescente. A parentalidade é algo construído pelo sujeito não sendo, necessariamente, exercida apenas pelo pai e mãe biológicos (GORIN et al., 2015, grifo nosso).

De acordo com Bronfenbrenner (2011, p. 282) é no microssistema familiar onde ocorrem as "primeiras e principais interações sociais da criança, onde se inicia a aprendizagem de conceitos, regras e práticas culturais que fundamentam os processos de socialização dos indivíduos", sendo considerada a primeira fonte de informação para a criança. Para o autor, a escola, sendo um espaço de convívio social, se constituiria na segunda fonte de informação para a criança, propiciando as 
interações com os pares e com os professores. Assim, intervenções voltadas para a interação família escola podem contribuir para o desenvolvimento integral da criança.

Assim como a família, a escola também é um microssistema (conjunto de relações entre a pessoa e o meio circundante imediato, (COELHO; DIAS, 2016) e precisa promover ações pensando em um mundo globalizado, tendo como tarefa preparar, não somente as crianças, mas também os profissionais que a compõem, sejam eles professores, gestores ou comunidade escolar (PETRUCCI; BORSA; KOLLER, 2016, p. 5).

A educação é um processo que vem se desenvolvendo ao longo do tempo visando transmitir não somente conhecimentos, mas também "valores, ideias e crenças" indo muito além da instituição escolar, e transitando em instituições sociais como a família, a igreja e o trabalho (FREITAS; FREITAS, CAVALCANTE, 2021, p. 3). A diferença entre essas instituições, conforme Silva (2017), é que "a ação educativa que decorre na escola obedece a um currículo, a metodologias e processos didáticos assegurados por professores [...]", diferentemente da educação informal que acontece em casa, na comunidade, e na sociedade em geral.

Vários estudos têm sido conduzidos enfatizando a importância do mesossistema ( interações entre aqueles que cercam o indivíduo) (COELHO; DIAS, 2016) família e escola no processo de ensino aprendizagem, contribuindo assim, para o bom desempenho do estudante (FREITAS; FREITAS; CAVALCANTE, 2021; MARTY; BONETTI, 2018). Parolin (2010), afirma que a escola deve ser uma grande parceira da família, assim como a família deve ser uma grande parceira da escola. Ambas têm um papel de educador a ser cumprido. A família cabe o papel formador, de acolher, promover e construir a individuação e pertencimento ao grupo familiar, ofertar limites, partilhar valores e ideias, enquanto à escola cabe o papel de socializar o conhecimento produzido. Para Piaget, o "vínculo escola-família prevê o respeito mútuo entre pais e professores", onde os papéis de pais e professores 
estão bem delimitados, não se confundem, assegurando que os pais opinem e ouçam os professores sem receio de serem avaliados e criticados (GERDES et al., 2020, p. 14).

O dia 24 de abril foi instituído pelo Ministério da Educação como o Dia Nacional da Família na Escola com intuito de ressaltar a importância da participação ativa dos pais e familiares nas atividades tanto pedagógicas quanto socializadoras desenvolvidas pela escola. (MENEZES, 2001).

A partir do que foi exposto surgiu, então, o questionamento: Existe interação entre as famílias de escolares do terceiro ano do ensino fundamental e a escola estadual a que pertencem? Identificar em que situações ocorre a participação das famílias de escolares do terceiro ano do ensino fundamental junto à escola foi o objetivo geral desse trabalho. Elencamos como objetivos específicos: Verificar em quais situações as famílias se sentem motivadas a frequentar a escola; Determinar qual a importância aferida pelos/as professores/as à participação das famílias na escola; Conhecer a opinião das crianças acerca da presença das famílias no ambiente escolar.

\section{MATERIAIS E MÉTODOS}

Com relação à abordagem adotada a pesquisa foi qualitativa. De acordo com Minayo (2008, p. 57)

O método qualitativo é adequado aos estudos da história, das representações e crenças, das relações, das percepções e opiniões, ou seja, dos produtos das interpretações que os humanos fazem durante suas vidas, da forma como constroem seus artefatos materiais e a si mesmos, sentem e pensam.

A pesquisa foi descritiva com relação aos seus objetivos, ou seja, pretendeu descrever fatos ou fenômenos de uma determinada realidade, segundo Triviños (1987). 
Quanto aos procedimentos técnicos adotados a pesquisa foi de Campo. Segundo Gil (1999, p. 5) nos estudos de campo

\begin{abstract}
a pesquisa é desenvolvida por meio da observação direta das atividades do grupo estudado e de entrevistas com informantes para captar suas explicações e interpretações do que ocorre no grupo. Esses procedimentos são geralmente conjugados com muitos outros, tais como a análise de documentos, filmagem e fotografias.
\end{abstract}

A pesquisa contou com 27 participantes, sendo 17 crianças escolares, nove responsáveis e uma professora. As crianças pertenciam a uma turma do terceiro ano do ensino fundamental composta por 12 meninos e cinco meninas, com idade entre oito anos e 12 anos. A entrevista foi realizada com 15 crianças, pois dois não compareceram às aulas no período em que se desenvolveu a pesquisa. As crianças residem no mesmo território onde a escola está inserida ou bairros próximos e pertencem a famílias que recebem apoio federal através do Programa Bolsa Família. A professora entrevistada, graduada em pedagogia e concursada pelo estado, atua há 38 anos no magistério e era regente da turma de terceiro ano. Segundo suas palavras, "ser professora foi minha primeira e única escolha, pois amo o que faço". Os nove responsáveis que se dispuseram a participar eram mães, pai, avó, tio, tia e moravam no mesmo domicílio que a criança.

O critério de inclusão adotado para a escolha da escola foi ser uma escola de periferia em situação de vulnerabilidade social e econômica. A definição por uma turma de terceiro ano foi em decorrência de estar realizando o estágio nos anos iniciais do ensino fundamental durante o período. A inclusão dos responsáveis se deu mediante confirmação de que as crianças residiam com eles. Acrescenta-se que todas as crianças tiveram voz na pesquisa, significando que foram perguntadas diretamente se desejavam participar da conversa com a pesquisadora. No que concerne as considerações éticas tanto os pais quanto a professora assinaram um Termo de Consentimento Livre e Esclarecido. Os responsáveis pelas crianças foram questionados com relação à permissão para conversar informalmente com elas. Foram-Ihes mostradas as perguntas que seriam feitas a fim de assegurar total 
transparência ao estudo. As crianças também foram questionadas se gostariam de participar, contudo, de forma lúdica, durante um jogo com bola.

A escola onde a pesquisa foi realizada é uma escola estadual localizada em um território de vulnerabilidade social., onde a maioria dos moradores são de baixa renda, sendo beneficiários do "Programa Bolsa Família". Define-se território como espaço geográfico, histórico, cultural, social e econômico que é construído coletivamente e de forma dinâmica por uma série de sujeitos e instituições que aí se localizam e circulam (BRASIL, 2009b). O Programa Bolsa Família (PBF) é um programa de transferência direta de renda, direcionado a famílias com renda per capita de até $R \$ 140,00$, que se encontram em situação de pobreza ou extrema pobreza. (BRASIL, 2006).

A escola integra ainda o Programa Escola Aberta para a Cidadania, vinculado ao Programa de Prevenção à Violência, oferecendo atividades diversificadas a comunidade durante os finais de semana, com oficinas de informática, artesanato, dança, esporte e lazer. Este programa realiza-se em algumas escolas públicas e foi elaborado pela Secretaria de Educação do Governo do Estado do Rio Grande do Sul, em parceria com a UNESCO com o objetivo de promover a cultura da paz e tentar minimizar as ações violentas ocorridas nas escolas e em seu entorno bem como proporcionar aprendizados diversificados a partir das oficinas ministradas, aos finais de semana, no espaço físico das escolas. De acordo com a Secretaria, o Programa Escola Aberta para a Cidadania constitui-se como uma "política de fomento ao fortalecimento da participação social e democrática do cidadão, iniciou em 2003 na rede pública estadual e tornou-se Política Pública em 2007, através da lei $n^{\circ} 12.865 / 2007$ e regulamentado pelo decreto $n^{\circ} 45.464 / 2008$ ".

Os dados foram coletados através de observação participante no período de 16 a 31 de outubro de 2019, no turno da tarde, e registrados em um Diário de Campo. A rotina escolar das crianças foi observada desde o momento da chegada até o momento da saída delas da escola. Ocorreu conversa informal com as crianças, e 
entrevista semiestruturada com uma professora e familiares das crianças. De acordo com Angrosino (2009) a observação participante refere-se à observação que acontece com o pesquisador desempenhando um papel ativo no contexto observado. A observação participante sugere saber escutar, ver, fazer uso dos sentidos. É preciso atentar para quando perguntar e quando não perguntar, e qual a hora certa para perguntar, sendo as entrevistas formais são muitas vezes desnecessárias (WHYTE, 2005, p. 304).

A estratégia utilizada para entrevistar os familiares foi esperá-los no início e ao final da aula na entrada da escola. Como nem todos os responsáveis levavam a criança até a escola foram entrevistados nove familiares. Acrescenta-se e enfatiza-se a intenção desde o início de realizar o estudo com a participação ativa das crianças. A pesquisadora acredita na importância de ouvir o que a criança tem a dizer, criança é sincera, diz o que pensa, o que sente, e não teria sentido fazer um trabalho envolvendo a criança sem a sua participação direta.

Em referência à entrevista, Lüdke (1986, p.33) menciona que:

[...] é importante atentar para o caráter de interação que permeia a entrevista. Mas que os outros métodos de pesquisa, que em geral estabelecem uma relação hierárquica entre o pesquisador e o pesquisado, como na observação unidirecional, na entrevista a relação que se cria é de interação, havendo atmosfera de influência recíproca entre quem pergunta e quem responde.

Para Lewgoy e Arruda (2004, p. 123-124), o Diário de Campo é um instrumento que permite "o exercício acadêmico na busca da identidade profissional" à medida que, através de aproximações sucessivas e críticas, pode-se realizar uma "reflexão da ação profissional cotidiana, revendo seus limites e desafios". Kroef; Gavillon e Ramm (2020) apontam que o Diário de Campo se constitui em práticas de escrita onde 0 pesquisador relata $\circ$ que vê, mas também $\circ$ que sente durante as observações.

\section{ANÁLISE E DISCUSSÃO DOS RESULTADOS}


A análise do material coletado deu-se em três etapas: Na primeira etapa, de posse das anotações do diário de campo e da realização da transcrição e leitura das entrevistas, estabeleceu-se um primeiro contato com os textos, com o objetivo de reconhecer os sentidos que as crianças, professora e familiares deixaram transparecer em suas falas. Na segunda etapa, identificou-se as palavras, ideias, ou frases que indicassem convergências e divergências dos participantes em relação à temática do estudo. Na terceira e última etapa, organizou-se e fez-se o mapeamento das semelhanças e diferenças das falas dos sujeitos, realizando várias releituras das transcrições das entrevistas. O objetivo foi confirmar os eixos de análise, previamente estabelecidos como objetivos específicos da pesquisa. Dessa forma, os eixos de análise que orientaram a apresentação dos resultados foram os seguintes: Eixo Criança: opinião das crianças acerca da presença das famílias no ambiente escolar; Eixo Família: em quais situações as famílias se sentem motivadas a frequentar a escola; Eixo Professora: Determinar qual a importância aferida pelos/as professores/as à participação das famílias na escola.

\section{EIXO CRIANÇA}

Perguntou-se às crianças se elas gostavam que o/a responsável as levasse e frequentasse a escola e todas responderam que sim, com exceção de um menino de oito anos que mora com os avós e irmão que não quis responder. Foi interessante notar que todas as crianças que não fazem parte de uma família nuclear, "aproveitaram" a pergunta e disseram que gostariam de morar com a mãe e que ela as levasse para a escola. Assim, a figura materna parece ter uma importância muito grande na vida dessas crianças independente de se fazerem presentes ou não. Abaixo algumas falas:

\footnotetext{
"Eu gostaria muito de morar com a minha mãe"

"Porque me sinto seguro com a minha mãe me trazendo"

"A minha mãe é legal"
}

RC: 93528

Disponível em: https://www.nucleodoconhecimento.com.br/educacao/integral-dacrianca 
O ingresso no estágio de operações concretas ( 7 aos 12 anos) de Piaget permite às crianças pensar logicamente e fazer julgamentos morais mais maduros (PAPALYA; OLDS; FELDMAN, 2009, p. 376). Além disso, as crianças no estágio de operações concretas compreendem melhor as relações espaciais, possuindo uma ideia mais clara da distância entre um lugar e outro e de quanto tempo levam para chegar; têm mais facilidade para se lembrar do trajeto e de seus pontos de referência, ou seja, estão aptas a irem para a escola sozinhas, não irão se perder, mesmo assim a figura materna é expressivamente importante nesse trajeto (PAPALYA; OLDS; FELDMAN, 2009, p. 365).

Morar com os pais ou ter uma mãe em casa, que não trabalha, não foi garantia para a criança ter ajuda parental na realização do "dever de casa". Somente em dois casos, onde a criança mora com os pais, que eles ajudam com as tarefas. Um menino de oito anos morando com avó, mãe revendedora de cosméticos e pai desempregado tem ajuda da irmã no dever de casa. Por outro lado, uma mãe faxineira, com dois filhos e que sustenta a casa sozinha, encontrou tempo para ajudar a filha com as tarefas da escola. Estudo conduzido por Umran (2019, p. 322) mostrou que "os pais de crianças com bom desempenho escolar" envolvem-se nas atividades escolares dos filhos, reservando tempo para auxiliar com os deveres; controlam o tempo que as crianças passam assistindo à televisão e o que fazem depois da escola; ou seja, demonstram interesse pelas vidas das crianças, conversando com elas sobre a escola.

Ainda, no eixo criança, quatro meninas com nove anos de idade e 11 meninos com idade entre oito e 11 anos (idade média de 9,1 anos) foram perguntados de que forma vão para a escola. Das quinze crianças somente quatro responderam serem levadas pela mãe (uma menina e três meninos). Um menino é levado pelo pai, cinco crianças vão sozinhas, e as demais são levadas por irmão, tia ou padrinho. Ser menina ou ser menino não influenciou em como as crianças vão para a escola. Os resultados acima poderiam sugerir que a maior parte das mães trabalha e por isso não levam seus filhos à escola. Contudo, quando perguntamos com quem ficavam 
em casa no turno inverso ao da aula, das sete crianças que responderam, três ficam com a mãe, contudo não é a mãe quem as leva à escola. A presença da irmã ou do irmão bem como a da vó ou outro laço consanguíneo, aparecem com frequência na fala das crianças (DIÁRIO DE CAMPO, 18 de abril de 2020).

É na interação familiar que se configuram os traços da personalidade da criança, onde os mais velhos servem de modelo para os mais novos (CACCIACARRO; MACEDO, 2018). As relações familiares influenciam no desenvolvimento individual da criança; da sua interação com o coletivo e da mediação dela com o mundo, auxiliando-a no seu relacionamento com professores e colegas, visando um desenvolvimento social (JARDIM, 2006, p. 14). O modelo familiar nuclear composto por pai, mãe e filhos biológicos apareceu somente nos relatos de uma menina, dois meninos de nove anos, e dois meninos de oito anos. Por isso enfatizamos que não há mais espaço para falarmos de família ao invés de famílias. As configurações familiares mudaram, e de acordo com o Plano Nacional de Convivência Familiar e Comunitária (BRASIL, 2005) a família é uma organização em constante transformação, interagindo intimamente com o contexto e época a qual está situada. A figura do padrasto apareceu em três respostas, com irmãos "emprestados", filhos desses padrastos. Duas crianças moram somente com a mãe (monoparentalidade feminina), e quatro crianças moram ou com a avó, ou com avó e pai, ou com avó, pai e tia.

Estimativas sugerem que o número de mulheres que são responsáveis únicas pelo sustento da casa aumentou 17\% entre 2000 e 2010 (IBGE, 2012). Aqui chamamos atenção que as famílias monoparentais femininas nem sempre são produto de uma separação conjugal. A mulher pode ser solteira e não ter tido uma gravidez planejada, pode ter sido uma adolescente e ter engravidado precocemente, ou ainda ser viúva. Na realidade, Pinto (2014) aponta que muitas mulheres em situação de vulnerabilidade social, morando nas periferias urbanas, tem filhos provenientes de uma gravidez precoce ou não planejada, bem como provêm de famílias instáveis. A presença da avó ou avós no universo de três meninos e uma menina foi marcante 
nas suas falas. Muitos avós cuidam dos netos enquanto os pais trabalham. Também há casos em que os avós assumem o papel dos pais responsabilizando-se por aspectos financeiros, levar e buscar na escola, até a transmissão de valores e crenças (TRECHOS DO DIÁRIO DE CAMPO, 19 de abril de 2020).

\section{EIXO FAMÍLIA}

Nove membros familiares, um tio, uma tia, um avô, três avós e três mães, foram entrevistados com o objetivo de verificar em quais situações se sentem motivados a frequentar a 39 escola. A maior preocupação da família pareceu ser em relação ao desempenho e rendimento escolar da criança (cinco familiares, sendo uma tia, três avós e uma mãe). A preocupação em saber sobre as dificuldades apresentadas pela criança, mencionado por um tio e um avô, bem como seu comportamento e relacionamento com os colegas e a professora, mencionado por duas mães, também foram razões que motivam a família a procurar a escola. (DIÁRIO DE CAMPO, 22 de abril de 2020).

Tio: "Como já está no fim do ano, para saber das dificuldades que apresenta".

Tia: "Como mora comigo, tenho que estar sempre presente para saber o que acontece diariamente".

Avós: 1- "Para saber do andamento";

2- "A gente tem como um filho, então, procuramos dar o melhor e sempre estar na escola para saber como anda";

3 - "Tento estar sempre presente, ajudo nos temas, trago para a escola, porque esse é o bem mais precioso que possamos dar, nunca esquecerão o que a gente faz por eles, amo muito a minha neta".

Avô: "Porque são pequenos ainda e temos sempre que conversar com a professora."

Mães: 1 - "Para saber como anda o comportamento em sala de aula";

2 - "Para saber o relacionamento com a professora e com os colegas";

3 - "Para saber como anda na escola".

RC: 93528

Disponível em: https://www.nucleodoconhecimento.com.br/educacao/integral-dacrianca 
A escola está localizada em um território vulnerável e as famílias apresentam, numa escala microssocial, diferentes níveis de vulnerabilidade social, condicionados por fatores tais como renda, escolaridade, gênero. Pudemos observar diferentes conjuntos familiares sustentando a afirmação de Prado (2011, p. 17) que diz ser a família "uma instituição social que varia ao longo da história e até apresenta formas e finalidades diversas numa mesma época e lugar, conforme o grupo social que esteja sendo observado". Os motivos que levaram os familiares a irem na escola sugerem que eles se sentem responsáveis pela educação dos filhos, diferentemente do que afirma Costa e Souza (2019) que sustenta que os pais depositam na escola a maior responsabilidade pelo desempenho e rendimento da criança.

Ainda, de acordo com Soares e Miguel (2020), algumas famílias, cada vez mais envolvidas com as exigências sociais e profissionais, depositam nas escolas a missão educativa para seus filhos. O que observamos, na realidade, foi a transferência de responsabilidade do papel de mãe e de pai para avós e tios; ou então, crianças que moram com o pai e avó e cuja mãe viajou para outra cidade. Estas famílias são, em grande parte, associadas às situações de vulnerabilidade econômica, e em alguns casos a mulher é a provedora do sustento familiar assumindo também funções domésticas e de cuidado dos filhos, o que a vincula em trabalhos mal remunerados em tempo parcial ou intermitente conforme apontam Costa e Marra (2013).

Ao adotar a responsabilidade de cuidado dos netos, a avó acaba assumindo o papel da mãe, comportando-se de forma análoga no que se refere à criação dos netos. "A gente tem como um filho, então, procuramos dar o melhor e sempre estar na escola para saber como anda". Neste cenário, os avós ostentam várias funções, provêm apoio financeiro, permeiam as relações entre pais e filhos, e acabam assegurando estabilidade para os netos (CARDOSO, 2011).

Especificamente nessa turma do terceiro ano, alguns familiares formaram um grupo juntamente com a professora no Whattsapp, sugerindo a predisposição tanto das 
famílias quanto da professora em interagir, aproximarem-se e, também, permitindo um contato mais imediato com os familiares caso algo aconteça com as crianças no horário escolar. Esse comportamento igualmente pode indicar que a figura de referência dos responsáveis pelas crianças na escola é a professora e que não se sentem como fazendo parte dessa escola, no sentido de tomada de decisões, participação em projetos, oficinas, atividades comunitárias e que desconhecem o conceito de gestão democrática [pressupõe a participação efetiva dos vários segmentos da comunidade escolar - pais, professores, estudantes e funcionários em todos os aspectos da organização da escola, com autonomia, pluralidade, transparência e participação, segundo Ferreira (2000)].

Quando perguntados acerca da importância das reuniões escolares, os familiares responderam que é um momento importante onde há esclarecimento de dúvidas e acompanhamento dos estudos. Uma avó respondeu "é o momento que temos de perguntar tudo o que acontece com nossos filhos, suas notas, seu comportamento e se vai passar de ano". "A frequência dos familiares na escola é indispensável" diz o tio e as avós entrevistados; os demais familiares comentam que vão à escola "quando há uma solicitação ou para presenciar reuniões". Percebe-se que o grau de parentesco familiar não influencia na participação em reuniões promovidas pela escola, as 41 chamadas Reuniões de Pais e Mestres, que ao nosso ver deveriam mudar de nomenclatura, visto o já mencionado acerca das diferentes configurações de família.

A participação do responsável pela criança nas reuniões é importante no sentido de aproximá-lo da escola, de mostrar à criança que se interessa pela sua educação e bem-estar, de conhecer os responsáveis pelas outras crianças, de conhecer a estrutura da escola e conhecer possíveis dificuldades ou aptidões da criança. Arruda (2019), corrobora com o modelo piagetiano, onde o escola e família compõem espaços igualmente importantes quando há escuta e respeito pelos diferentes papeis que desempenham, mas com objetivo comum de contribuir para o 
desenvolvimento da criança (TRECHOS DE DIÁRIO DE CAMPO/ PROFESSORA. ABRIL, 2020).

Oliveira e Lopes (2019) abordam a importância de os professores conhecerem quais são as experiências das crianças fora da escola, assim como a compreensão dos pais se enriquece quando tomam conhecimento de como é o cotidiano de seus filhos junto aos educadores e às demais crianças. $E$ nada mais espontâneo e natural do que conversar, relatar fatos, situações e trocar ideias. Segundo Parolin (2010), à família cabe o papel formador de acolher, promover e construir a individuação e pertencimento ao grupo familiar, ofertar limites, partilhar valores e ideias, enquanto à escola cabe o papel de socializar o conhecimento produzido.

Segundo Yoba (2018), família é um conjunto de pessoas que se encontram unidas por laços de parentesco, e tais laços de parentesco podem ter uma sustentabilidade inicial com a união por casamento, afinidade ou adoção. As configurações familiares são diversas, contudo, a família continua sendo um sistema potente para a construção da identidade, o desenvolvimento da empatia e elaboração do que é certo e errado. E, segundo Souza e Schnitman (2021) é essa conexão afetiva e amorosa que favorece o bom desempenho escolar da criança. É na interação familiar que se configuram os traços da personalidade da criança, onde os mais velhos servem de modelo para os mais novos (SOUZA, SCHNITMAN, 2021).

\section{EIXO PROFESSOR}

Quando questionada sobre qual a importância que aferia à participação das famílias na escola, a professora afirmou ser de extrema importância pois

"a interação e a parceria entre família e escola é vital para o sucesso no desenvolvimento intelectual, moral e na formação do educando, sentindo-se assim, motivados, interessados e comprometidos em relação a aprendizagem, aspecto esse, demonstrado através do rendimento escolar e nas reações e atitudes dos educandos".

RC: 93528

Disponível em: https://www.nucleodoconhecimento.com.br/educacao/integral-dacrianca 
A fala da professora vai de acordo com Paro (2007), que enfatiza a importância da aproximação entre família e escola no processo de ensino aprendizagem, contribuindo assim, para o bom desempenho do educando.

As respostas corroboram com Libâneo (2002) que diz ser a característica mais importante da atividade profissional do professor a mediação entre o aluno e a sociedade, entre as condições de origem do aluno e sua destinação social na sociedade, pois "o processo de ensino é ao mesmo tempo um processo de educação" (LIBÂNEO, 2002, p. 71).

Ao ser questionada sobre como as famílias poderiam ser mais participativas na escola a professora mencionou a necessidade de se resgatar "algumas brincadeiras" com as crianças, pois atualmente "só estão nos celulares"; dessa forma os responsáveis poderiam participar contando histórias, atividades recreativas praticadas em sua infância como pular elástico, cama de gato, jogo das três Marias, além de confecção de artesanato e gincanas. A resposta da professora não pareceu clara pois ela não conseguiu definir em que momento as famílias iriam participar resgatando as brincadeiras supracitadas. Nota-se, também, que a professora atribuiu às famílias atividades predominantemente práticas dando a entender que elas não teriam condições de contribuir de outra forma com a escola.

Ao ser questionada acerca do grau de comprometimento e envolvimento dos pais em relação à educação dos filhos a professora comentou que

os nossos alunos na maioria são carentes de carinho, de atenção e afeto. Poucos são os pais que demonstram interesse pela vida escolar de seus filhos, que participam das atividades escolares e se fazem presentes na escola. Alguns alegam que por trabalharem fora não dispõem de tempo e isso acontece muito, principalmente, na data de entrega dos pareceres.

A professora não especificou em quais as atividades escolares, além da data de entrega dos pareceres, os responsáveis eram ausentes, tão pouco pareceu conhecer a realidade das crianças visto desconhecer que muitas delas não residem com os pais. Enfatizamos que essa é a visão da professora e que alguns

Disponível em: https://www.nucleodoconhecimento.com.br/educacao/integral-dacrianca 
responsáveis mencionaram que quando precisam contatar a professora o fazem via grupo do Whattsapp. Talvez a pouca participação desses pais, das atividades escolares, seja decorrente da sensação de proximidade gerada pelo aplicativo fazendo com que os responsáveis pela criança não sintam o mesmo distanciamento que a professora. Talvez a avó, o avô, a tia, o tio, a mãe, o pai, não tenham condições de serem mais presentes por motivos diversos, como saúde, trabalho, e até mesmo um baixo nível educacional pode pesar na hora de participar ou não de alguma atividade na escola. As dinâmicas familiares são complexas. Para muitas famílias assegurar a frequência da criança à escola é o objetivo principal. Empregam esforços que devem ser valorizados para que a criança esteja todos os dias, na mesma hora, na escola, lugar que permitirá àquele membro da família ter um futuro melhor do que o seu responsável tem no momento presente. O que a criança necessita é de comunicação com afeto, conhecer os motivos pelos quais seu responsável não pode buscar o parecer ou ir à festa junina é tão importante quanto a própria presença no evento.

É importante salientar que estamos nos referindo a uma escola situada em uma zona afastada do centro, e de familiares de baixa renda que residem em bairros próximos da escola, sendo beneficiários do Programa Bolsa Família. Portanto, estamos diante de um cenário de vulnerabilidade das famílias e de vulnerabilidade do território onde a escola se encontra e esse contexto social não deve ser desprezado quando interpretamos a fala, seja da professora, seja do responsável, seja da criança.

A professora respondeu que o que mais impulsiona a escola a se comunicar com os pais é "a oportunidade de conhecer a história de vida do nosso aluno, para melhor entendê-lo, atendê-lo e compreendê-lo no seu desempenho pedagógico, cognitivo e no procedimento de suas relações e atitudes". Na escola, a criança irá vivenciar desafios que poderão ser superados com acolhimento e intervenção da professora. Contudo, esse processo ocorre mais naturalmente se a realidade do aluno é conhecida, tornando-se mais fácil compreender suas atitudes. 
Segundo Castro e Regattieri (2009, p.6) "quando a escola melhora seu conhecimento e compreensão sobre os alunos, sua capacidade de comunicação e adequação das estratégias didáticas aumenta e, em consequência, aumentam as chances de um trabalho escolar bem-sucedido". Corroborando com Castro e Regattieri, Costa, Silva e Souza (2019) destacam a importância de os professores conhecerem quais são as experiências das crianças fora da escola, assim como a compreensão dos pais se enriquece quando tomam conhecimento de como é o cotidiano de seus filhos junto aos educadores e às demais crianças. $E$ nada mais espontâneo e natural do que conversar, relatar fatos, situações e trocar ideias (COSTA; SILVA; SOUZA, 2019).

A professora também mencionou que percebe "melhora no rendimento escolar dos alunos" cujas famílias participam mais diretamente das atividades na escola, concordando com Costa; Silva e Souza (2019, p.4) que diz ser a "família e a escola parceiros importantes na elaboração de ações que favorecerão o sucesso escolar e social das crianças" Assim, a família e a escola operam como instrumentos interdependentes, que atuam conjuntamente para 0 sucesso do pleno desenvolvimento do educando (SIMÕES; COUTINHO, 2020).

A escola sendo um espaço de vida, deve acreditar no potencial das crianças dandoIhes o direito de serem protagonistas, de terem papel ativo na aprendizagem e na relação com os outros. Esse é o motor da educação (RASCHE; SILVA, 2021).

\section{CONSIDERAÇÕES FINAIS}

Neste estudo buscou-se responder à questão: Existe interação entre as famílias de escolares do terceiro ano do ensino fundamental e a escola estadual a que pertencem? Para isso elegeu-se como objetivo geral: Identificar em que situações ocorre a participação das famílias de escolares do terceiro ano do ensino fundamental junto à escola; e como objetivos específicos: Verificar em quais situações específicas as famílias se sentem motivadas a frequentar a escola; 
Determinar qual a importância aferida pelo/a professor/a à participação das famílias na escola; Conhecer a opinião das crianças acerca da presença das famílias no ambiente escolar.

Partiu-se, então, para os objetivos específicos e buscou-se conhecer a opinião das crianças sobre a importância da presença das famílias no ambiente escolar e todas foram unânimes em dizer que consideram importante. Entendeu-se pela fala das crianças que é muito marcante a figura da mãe para as crianças.

Com relação às situações que motivam as famílias a frequentarem a escola, foram citadas: a preocupação em conhecer as dificuldades apresentadas pela criança, bem como seu comportamento e relacionamento com os colegas e a professora. Algumas famílias consideraram a comunicação com a professora via aplicativo Whattsapp como uma forma de participação na vida escolar da criança, outros consideraram o envio de bilhetes para a professora como uma forma de comunicação efetiva.

Quando questionada sobre qual a importância que aferia à participação das famílias na escola, a professora afirmou ser de extrema importância. Acreditamos que o docente deve posicionar-se com empatia diante dos obstáculos encontradas por seus alunos, com olhar crítico e sensível sobre eles, com formação coerente e adequada, com afetuosidade para o entendimento de suas necessidades individuais, pois cada indivíduo é um ser único e cada um tem seu tempo e ritmo de aprendizagem.

Assim, identificou-se que as famílias depositam na escola a responsabilidade principal pela educação das crianças, uma vez que a escola é procurada para conhecerem as dificuldades da criança, comportamento e relacionamento.

Por fim respondeu-se à questão de pesquisa "existe interação entre as famílias de escolares do terceiro ano do ensino fundamental e a escola estadual a que pertencem" da seguinte forma: são diferentes configurações de famílias, mãe 
sozinha, pai que mora com avós da criança, pai e mãe, avó, avós, tio, enfim histórias de vida distintas, percepções do que é participar distintas. Talvez, na percepção de cada uma dessas pessoas exista interação pelo fato de irem buscar o parecer da criança na data e hora marcados. Por outro lado, a professora tem uma visão diferente e as crianças sentem a falta de uma participação maior dos responsáveis.

Essa pesquisa permitiu refletir o quão importante é o conhecimento de nossos direitos, o conhecimento das diferentes formas de participação e de que as famílias desconhecem que fazem parte da comunidade escolar. Permitiu refletir que a parceria entre a escola e a família exige de ambas as partes dedicação e posicionamento, jamais esquecendo que esta relação só existe porque há uma vida em comum, que é a vida da criança. Permitiu refletir que muitas vezes essa dedicação não acontece porque as famílias estão demasiado preocupadas em colocar o alimento na mesa, em pagar o aluguel ao final do mês, em levantar-se cedo para pegar ficha na unidade básica de saúde, ou em pegar o ônibus mais cedo pois depois ele estará lotado. Permitiu refletir que o objetivo dessas famílias é assegurar escola para essa criança e muitas vezes a frequência é importante também pois condiciona ao recebimento do Bolsa Família. Permitiu refletir que aquela mãe que teria tempo de ir à escola não o faz porque não sabe como pode contribuir, sua mãe também não foi à escola e a mãe da sua mãe também não. Permitiu refletir que para ter posicionamento é necessário, formar uma opinião acerca de um assunto e tomar posição.

Acredita-se no poder da educação, acredita-se na escola acolhedora, acredita-se no professor empático, acredita-se no aluno carismático e acredita-se acima de tudo na família, quando essa é afetuosa com a criança, seja qual for a sua constituição.

\section{REFERÊNCIAS}

ANGROSINO, M. Etnografia e observação participante. Porto Alegre: Artmed, 2009. 
ARRUDA, Jerônimo Romano de. A relação da família com a escola e o mal-estar docente: família e escola, em busca da cumplicidade para um melhor aprendizado do aluno. Revista Inclusiones Vol: 6 num 2 : 26-45. 2019. Disponível em REVISTA INCLUSIONES (archivosrevistainclusiones.com). Acesso: 19/04/2020.

BRASIL. Conselho Nacional dos Direitos da Criança e do Adolescente - CONANDA. Plano Nacional de Promoção, Proteção e Defesa do Direito de Crianças e Adolescentes à Convivência Familiar e Comunitária. 2005. Disponível em Plano_Defesa_CriancasAdolescentes .pdf (mds.gov.br). Acesso em 29/06/2021.

BRASIL. Secretaria Nacional de Renda de Cidadania. Guia do gestor. Brasília: MDS, 2006. Disponível em: SISTEMA DE GESTÃO DO PROGRAMA BOLSA FAMÍLIA (mds.gov.br) Acesso em 21/04/2020.

BRASIL. Ministério da Educação e Cultura (MEC). Interação Escola-Família: subsídios para práticas escolares. 2009a. Disponível em: Interação escola-família: subsídios para práticas escolares; 2009 (mec.gov.br) Acesso em 21/04/2020.

BRASIL. Ministério da Saúde. Secretaria de Atenção à Saúde. Departamento de Atenção Básica. Saúde na escola / Ministério da Saúde, Secretaria de Atenção à Saúde, Departamento de Atenção Básica. - Brasília : Ministério da Saúde, 2009b. Disponível em: Saúde na escola (saude.gov.br) Acesso em 25/06/2020.

BRONFENBRENNER, U. Fortalecendo os sistemas da família. In Bronfenbrenner, Bioecologia do desenvolvimento humano: Tornando os seres humanos mais humanos (pp. 277-289). Porto Alegre, RS: Artmed. 2011.

CARDOSO, A.R. Avós do século XXI: mutações e rearranjos na família contemporânea. Curitiba: Juará Editora, 2011.

CASTRO, Jane Margareth e REGATTIERI Marilza. Interação escola-família: subsídios para práticas escolares. Brasília: UNESCO, MEC, 2009. 104 p. Disponível 
em: Interação escola-família: subsídios para práticas escolares; 2009 (mec.gov.br) Acesso em 10/05/2021.

Cacciacarro, Mariana; Macedo, Rosa Maria. A família contemporânea e a seus valores: um olhar para a compreensão parental. Psicol Rev. 24(2):381-401. 2018. Disponível em: A família contemporânea e seus valores: um olhar para a compreensão parental | Psicol. rev. (Belo Horizonte);24(2): 381-401, maio-ago. 2018. | LILACS (bvsalud.org). Acesso em 14/06/2021.

COELHO, Maria Teresa Barros Falcão ; DIAS, Cristina Maria. Inserção ecológica no contexto escolar: importância da observação da relação família-escola. Investigação qualitativa em saúde, vol. 2. 2016. Disponível em: 858-Texto Artigo-3384-1-1020160706.pdf Acesso em 26/06/2021.

COSTA, Emanuelle. L.; SOUZA, Jane R. S. Família e escola: as contribuições da participação dos responsáveis na educação infantil. Khóra: Revista Transdisciplinar, 6(7). 2019. Disponível em: FAMÍLIA E ESCOLA: AS CONTRIBUIÇÕES DA PARTICIPAÇÃO DOS RESPONSÁVEIS NA EDUCAÇÃO INFANTIL | Costa | Khóra: Revista Transdisciplinar (feuc.br) Acesso em 25/06/2021.

COSTA, Maria Aparecida da; SILVA, Francisco Mário Carneiro. da; SOUZA, Davison da Silva. Parceria entre escola e família na formação integral da criança. Práticas Educativas, Memórias e Oralidades - Rev. Pemo, [S. I.], v. 1, n. 1, p. 1-14, 2019. DOI: https://doi.org/10.47149/pemo.v1i1.3476. Disponível em: https://revistas.uece.br/index.php/revpemo/article/view/3476.

COSTA, Florença Avila.; MARRA, Marlene Magnabosco. Famílias brasileiras chefiadas por mulheres pobres e monoparentalidade feminina: risco e proteção. Revista Brasileira de Psicodrama, 21(1), 141-153. 2013. Disponível em: Famílias brasileiras chefiadas por mulheres pobres e monoparentalidade feminina: risco e proteção | Rev. bras. psicodrama;21(1): 141-153, 2013. | LILACS (bvsalud.org). Acesso em 14/07/2020. 
EDUCA BRASIL. Dia Nacional da Família na Escola. 2021. Disponível em: Dia Nacional da Família na Escola - EducaBrasil. Acesso em 15/07/2021.

FELIPPI, Geisa; ITAQUI, Luciara Gervasio. Transformações dos laços vinculares na família: uma perspectiva psicanalítica. Pensando fam. [online]. 2015, vol.19, n.1 , pp. $105-113$ Disponível em: http://pepsic.bvsalud.org/scielo.php?script=sci_arttext\&pid=S1679$494 X 2015000100009 \&$ Ing=pt\&nrm=iso Acesso em 14/07/2020.

FERREIRA, Naura Syria Carapeto . (org) Gestão Democrática da Educação: atuais tendências, novos desafios. 2ed São Paulo: Cortez, 2000.

FLICK, Uwe. Introdução à pesquisa qualitativa (3a ed., J. E. Costa, Trad.). São Paulo: Artmed. 2009.

FREITAS, N. L. D. de S.; ANJOS, D. F. dos. A articulação entre o livro de Hans Robert Jauss "a história da literatura com provocação à teoria literária", o conto de Lygia Bojunga "Tchau" e as novas construções familiares. Revista Prática Docente, [S. I.], v. 5, n. 2, p. 889-900, 2020. DOI: https://doi.org/10.23926/RPD.25262149.2020.v5.n2.p889-900.id832 Disponível em: http://periodicos.cfs.ifmt.edu.br/periodicos/index.php/rpd/article/view/832 Acesso em 30 de junho de 2021.

FREITAS, M. C. de, FREITAS, B. M.; CAVALCANTE, G. F. A importância da escola para crianças em contexto familiar monoparental. Ensino Em Perspectivas, 2(1), 113. 2021. Disponível em: https://revistas.uece.br/index.php/ensinoemp9erspectivas/article/view/4536 Acesso em 29 de junho de 2021.

FUNDAÇÃO ABRINQ. Cenário da Infância e Adolescência no Brasil 2021. Disponível em: Fundação Abrinq traça panorama da Infância e Adolescência no Brasil | FUNDAÇÃO ABRINQ (fadc.org.br). Acesso em 25 de junho 2021. 
GERDES, J.; GOEI, S.L.; HUIZINGA. M.; De RUYTER D.J. True partners? Exploring family-school partnership in secondary education from a collaboration perspective, Educational Review. 2020. DOI: 10.1080/00131911.2020.1778643. Disponível em: https://www.tandfonline.com/loi/cedr20 Acesso em 25 de junho de 2021.

GIL, Antônio Carlos. Métodos e técnicas em pesquisa social. São Paulo: Atlas, 207 p, 1999.

GOODALL Janet; Learning-centred parental engagement: Freire reimagined. Educational Review, 70:5, 603-621. 2018. DOI: 10.1080/00131911.2017.1358697 Acesso em 24 de junho de 2021.

GORIN, Michelle Christof et al . O estatuto contemporâneo da parentalidade. Rev. SPAGESP, Ribeirão Preto , v. 16, n. 2, p. 3-15, 2015 . Disponível em http://pepsic.bvsalud.org/scielo.php?script=sci_arttext\&pid=S167729702015000200002\&lng=pt\&nrm=iso Acesso em: 24/06/2020.

IBGE. Instituto Brasileiro de Geografia e Estatística. Síntese de indicadores sociais: Uma análise das condições de vida da população brasileira. Diretoria de Pesquisas. Estudos e Pesquisas - Informação Demográfica e Socioeconômica. Rio de Janeiro: IBGE. 2012

IBGE. Pesquisa Nacional por Amostra de Domicílios Contínua Anual., 2ํㅗㄴ semestre de 2019. Disponível em: Tabela 7141: Taxa ajustada de frequência escolar líquida, por sexo e faixa etária ideal por curso frequentado (ibge.gov.br). Acesso em 29 de junho de 2021.

IBGE. Instituto Brasileiro de Geografia e Estatística. Pesquisa Nacional por Amostra de Domicílios Contínua Anual: Características gerais dos domicílios e dos moradores 2019. ISBN 978-85-240-4530-1. IBGE, 2020. 
JARDIM, A. P. Relação entre Família e Escola: Proposta de Ação no Processo Ensino Aprendizagem. Presidente Prudente: Unoeste, 2006.

Kroef, Renata Fischer da Silveira; GAVILLON, Póti Quartiero; RAMM, Laís Vargas Diário de Campo e a Relação do(a) Pesquisador(a) com o Campo-Tema na Pesquisa-Intervenção Estudos e Pesquisas em Psicologia, vol. 20, núm. 2, 2020, pp. 464-480 Universidade do Estado do Rio De Janeiro DOI: https://doi.org/10.12957/epp.2020.52579

LEWGOY, A. M. B.; ARRUDA, M. P. Novas tecnologias na prática profissional do professor universitário: a experiência do diário digital. Revista Textos e Contextos: coletâneas em Serviço Social, Porto Alegre: EDIPUCRS, n. 2. 2004, p. 115-130.

LIBÂNEO, José Carlos. Pedagogia e Pedagogos, para quê? São Paulo: Cortez, 2002.

LÜDKE, M.; ANDRÉ, M. E. D. A. Pesquisa em educação: abordagens qualitativas. São Paulo: EPU, 1986.

MARTY, Marina dos Reis; BONETTI, Alline de Lima. Impacto das múltiplas organizações familiares na escola: "Outras famílias, outras histórias. Rev Ciências Humanas e Sociais: Missões, v.4, n. 4, p. 80 - 90. 2018. Disponível em: IMPACTO DAS MÚLTIPLAS ORGANIZAÇÕES FAMILIARES NA ESCOLA: "OUTRAS FAMÍLIAS, OUTRAS HISTÓRIAS" | Missões: Revista de Ciências Humanas e Sociais (unipampa.edu.br) Acesso em 26/06/2021.

MENEZES, Ebenezer Takuno de; SANTOS, Thais Helena dos. Verbete Dia Nacional da Família na Escola. Dicionário Interativo da Educação Brasileira -Educabrasil. São Paulo: Midiamix, 2001. Disponível em: http://www.educabrasil.com.br/dia-nacionalda-familia-na-escola/. Acesso em 01 de abr. 2019. 
MINAYO, Maria Cecília de Souza. O desafio do conhecimento. 11 ed. São Paulo: Hucitec, 2008.

OLIVEIRA, Irany Alves; LOPES, Eliete Borges. Relação família e escola visando o aprendizado do educando. GEOGRAFIA: Ambiente, Educação e Sociedades GeoAmbES, jan./jun. vol. 3, n. 1, p. 113- 124, 2020. Disponível em: RELAÇÃO FAMÍLIA E ESCOLA VISANDO O APRENDIZADO DO EDUCANDO | OLIVEIRA | GEOGRAFIA: Ambiente, Educação e Sociedades (unemat.br) Acesso em: 15/06/2021.

PAPALIA, D. E.; OLDS, S. W.; FELDMAN, R. D. Desenvolvimento humano. Porto Alegre: Artmed, 2009

PARO, Vitor H. Qualidade do Ensino: contribuição dos pais. 3a ${ }^{\text {a }}$ reimp. São Paulo: Xamã, 2007.

PAROLIN, Isabel. Professores Formadores: A relação entre a Família, a Escola e a Aprendizagem. $2^{\circ}$ ed. São José dos Campos, SP. Pulso Editorial.

PETRUCCI, Giovanna Wanderley; BORSA, Juliane Callegaro; Koller, Sílvia Helena. A Família e a Escola no Desenvolvimento Socioemocional na Infância. Temas em Psicologia. 2016. Disponível em: http://pepsic.bvsalud.org/scielo.php?script=sci_arttext\&pid=S1413389X2016000200001. Acesso em 11 mai. 2019.

PINTO, Joice Carvalho. Projeto de intervenção para prevenção de casos de gravidez na adolescência no município de Alvorada de Minas. Trabalho de Conclusão de Curso (Especialização) - Universidade Federal de Minas Gerais. Araçuai, MG: 2014. Disponível em: https://ares.unasus.gov.br/acervo/html/ARES/5467/1/4774.pdf Acesso em 21 de junho de 2021. 
PRADO, Danda. O que é família. São Paulo: Brasiliense, 2011. Coleção Primeiros Passos.

RASCHE, Amanda Cristina; SILVA, Jacqueline. Silva da. O que as crianças pensam sobre a investigação? Revista Signos, [S.I.], v. 42, n. 1, jun. 2021. Disponível em: http://www.univates.br/revistas/index.php/signos/article/view/2682. DOI:http://dx.doi.org/10.22410/issn.1983-0378.v42i1a2021.2682.

RIO GRANDE DO SUL. RS. Secretaria de Educação. Estatísticas da Educação. Censo de 2017.2 Disponível em: http://servicos.educacao.rs.gov.br/pse/srv/estatisticas.jsp?ACAO=acao1. Acesso em: 10 mai. 2021.

RIO GRANDE DO SUL. RS. Secretaria de Educação. Escola aberta para a cidadania. Disponível em: https://educacao.rs.gov.br/escola-aberta-para-a-cidadania SILVA, Eugênio Alves. Educação, Gestão Escolar e Projeto Educativo, in Educação e Desenvolvimento Local. $1^{\circ}$ Fórum Provincial da Educação da Huila. ECO7 Investimentos, Ltda. Luanda, 2017.

SIMÕES Emília, DF; COUTINHO Diógenes JG - A relação família e escola no processo ensino-aprendizagem do educando. Brazilian Journal of Development. Curitiba, v. 6, n. 1, p. 4309-4320, jan. 2020.

SOARES, Maria Socorro; MIGUEL, Joelson Rodrigues. Escola: concepções históricas e a influência da família no processo de aprendizagem. Id on Line Rev. Mult. Psic. V.14, N. 51 p. 667-679. ISSN 1981-1179. 2020. DOI: https://doi.org/10.14295/idonline.v14i51.2627 Acesso em 29 de junho de 2021.

SOUZA, Sara Helen. dos Santos. de., SCHNITMAN, Ivana Maria. O uso da internet por adolescentes e as transformações nas relações de poder da família contemporânea. REVES - Revista Relações Sociais, 4(2), 11605-01. 2021. DOI: 
https://doi.org/10.18540/revesvl4iss2pp11605-01-19e Acesso em 28 de junho de 2021.

TRIVIÑOS, Augusto Nibaldo Silva. Introdução à Pesquisa em Ciências Sociais: A Pesquisa Qualitativa em Educação. São Paulo. 1987.

UNICEF BRASIL. Situação das crianças e dos adolescentes no Brasil. Disponível em: Situação das crianças e dos adolescentes no Brasil (unicef.org). Acesso em 29 de junho de 2021.

UNICEF BRASIL, CENPEC EDUCAÇÃO. Cenário da Exclusão Escolar no Brasil um alerta sobre os impactos da pandemia da Covid-19 na Educação. 2021. Disponível em: Crianças de 6 a 10 anos são as mais afetadas pela exclusão escolar na pandemia, alertam UNICEF e Cenpec Educação. |Acesso em 29 de junho de 2021.

WHYTE, William Foote. Sociedade de esquina: a estrutura social de uma área urbana pobre e degradada. Tradução de Maria Lucia de Oliveira. Rio de Janeiro, Jorge Zahar, 2005. 390 páginas.

YOBA, Carlos Pedro Cláver. Participação da família e da escola na educação dos jovens. Revista Construção Psicopedagógica, 26 (27): 13-20. 2018. Disponível em 03.pdf (bvsalud.org). Acesso em 27/06/2021.

UMRAN, Sahin. Parents' Participation Types in School Education. International Journal of Educational Methodology, v5 n3 p315-324 2019. Disponível em: ERIC EJ1225563 - Parents' Participation Types in School Education, International Journal of Educational Methodology, 2019 Acesso em 24/06/2021.

Enviado: Julho, 2021.

Aprovado: Agosto, 2021. 